\title{
Who is "us"? Students negotiating discourses of racism and national identification in Australia
}

\author{
Julie McLeod and Lyn Yates
}

\begin{abstract}
This article explores the political beliefs and the forms of reasoning about racism, national identity and Other developed by young Australian women and men from different ethnic and class backgrounds. The interviews on which the discussion is based are drawn from a larger longitudinal study of Australian secondary school students which examines how young people develop their sense of self and social values over time. The present article here has two overall purposes: to add to understandings of how the cultural logic of racism functions in one national setting, and to consider political reasoning about race and ethnicity in relation to processes of young people's identity positioning. Three main lines of argument are developed. The first concerns students' positioning of themselves vis a vis the current 'race debate' in Australia, and in relation to us as researchers, including their negotiation of the protocols for speaking about 'race' and racism. This includes consideration of the methodological and political effects of white Anglo women asking question about racism and ethnicity to ethnic-minority students who are routinely constituted as 'Other': what blindnesses and silences continue to operate when posing questions about racism directly? A second and related focus is the range of emotional responses evoked by asking questions about racism and about an Australian politician [Pauline Hanson], who has been prominent in race debates. Third, we examine young people's construction of 'us and them' binaries and hierarchies of Otherness and whiteness. We argue throughout that reasoning about race, national identity and Others, and the taking up of 'political positions', is intimately linked to identity formation and to how we imagine ourselves in the present, the past and the future.
\end{abstract}


Who is "us"? Students negotiating discourses of racism and national identification in Australia

What forms of reasoning, and what processes of identification are young people involved in as they enunciate 'political positions' or views on racism and the composition of their nation? In a comparative study of US and French 'rhetorics of racism and anti-racism,' Michele Lamont attempts to 'reconstruct the mental maps and symbolic boundaries through which ... individuals define "us" and "them"'. She argues that these show how 'people define their own identity and the identity of their community, or the boundaries through which they distinguish between people like themselves with whom they identify and Others' (Lamont 2000, p.25). We develop a related 'double focus' on identity here by looking at how young people position and represent themselves in relation to their views about race and national identity and, in doing so, explore the construction of race and nationalist discourses in contemporary Australia. But researching racism and attitudes to race and ethnicity is not a straightforward matter, not least because of the strong emotional response the topics can evoke for both interviewer and participants, and their resonance with different political and identity positions. It is also a topic that amplifies the constructing role of the researcher and the methodological and interpretive significance of who is asking questions of whom.

We are two Anglo-Australian, middle-class, professional women asking questions about race, racism, and migration to young women and men from a range of different ethnic and class backgrounds. These identity positions do shape what we ask and what we hear, and how students respond to us and our questions. With these issues in mind, our intention, nevertheless, is to explore views and reasoning about race and ethnicity in order to add to understandings of 'how the cultural logic of racism functions' (Lamont 2000, p.28) in one national setting, and in relation to processes of young people's identity positioning.

What it means to be an 'Australian' is currently the subject of much public contest, and the politics of race, ethnicity and nationalism are tightly bound together. Questions of how national identity is 
understood, and what the key issues and points of contention are vary between different national settings. For example, in the countries Lamont compares, the US and France, national identity is linked to traditions such as school-based civics, and declaration of rights of the individual, and in France to a strong pride in and government programs to support a common 'national culture'. Looking at discourses about race, ethnicity and nation in cultures where the 'taken-for-granteds' are very different, in this case Australia, offers a way to avoid essentialist, universalising and stereotyped understandings of the relations between these discourses and politics.

Numerous studies have been set up to examine students' views on racism and racial and ethnic difference and identities (e.g. Rizvi 1993; Roman \& Stanley 1997; Nayak 1999; Dolby 2000). But the analysis developed here emerges from a study framed differently, one in which attitudes to racism or multiculturalism have not been the primary or exclusive focus of enquiry. The longitudinal project on which this discussion draws (The 12 to 18 Project $^{1}$ ) is concerned with how young people develop their sense of self and social values over time. It was designed to reflect on the ways in which popular or dominant social discourses are mobilised and individual biographies are shaped in different school contexts. One of the reasons for asking questions about race and racism was to gain some insight into students' political sensibilities and modes of thinking in terms of their developing biographies. We raised the questions also because at the time these interviews took place, such questions were matters of considerable public political debate in Australia.

\footnotetext{
112 to 18 Project is a qualitative, longitudinal study of Australian secondary school students that began in 1993 when the students were at the end of primary school and concluded in 2000, when the majority of students had finished school. The Project has two broadly comparative dimensions. It develops comparisons between groups of students attending four different co-educational schools: a large, elite private college, a state metropolitan 'arty' secondary school, and two secondary schools in the same provincial town, one a former technical school and the other a traditional academic high school. It compares gender, class, and ethnic differences across the study. It also examines the development of subjectivity over time and attempts to understand changes and continuities within individuals, building up a picture of how young people's attitudes, sense of self, relation to school and so on develops and compares at different stages of their growing up. Students were interviewed and video-taped twice each year and three themes in particular were explored: students' changing relation to schooling; their views and understandings of the future and; the ongoing construction of their gender/class subjectivity. (Yates \& McLeod 1996; McLeod \& Yates 1997; McLeod 2000; Yates 2000). The study has received funding from the Australian Research Council, La Trobe University, Deakin University and University of Technology, Sydney.
} 
In late 1997, we asked Year 10 students (26 students aged fifteen and sixteen years old, whom we followed over our eight year project) from four different schools a series of questions on political and ethical issues. Here we examine several main themes that emerged in responses from students at all four schools to questions about racism in Australia, the politics of Pauline Hanson (the leader of a populist and controversial political party which opposed alleged special treatment of Indigenous people and migrants), Aboriginal issues and migration. The first theme concerns students' positioning of themselves vis a vis the current 'race debate', and in relation to us as researchers, including their negotiation of the protocols for speaking about 'race' and racism. This includes consideration of the methodological and political effects of white Anglo women asking question about racism and ethnicity to ethnic-minority students who are routinely constituted as 'Other': what blindnesses and silences continue to operate when posing questions about racism directly? In retrospect, for example, we can see how our mode of questioning positioned these students simultaneously as Others and as knowledgeable commentators upon racism. A second and related theme threaded throughout the discussion is the range of emotional responses evoked by asking questions about racism and the reception of Pauline Hanson. Third, we examine young people's construction of 'us and them' binaries and hierarchies of Otherness and whiteness in terms of understanding both contemporary debates about race and racism in Australia and processes of self-identification. We argue throughout that reasoning about race, national identity and Others and the taking up of 'political positions' is intimately linked to identity formation and to how we imagine ourselves in the present, the past and the future.

\section{The politics of race in Australia in the 1990s}

During the 1990s a number of events signified an intensified focus on the politics of race and national identity in Australia. The High Court's ruling on 'Native Title' ['The Mabo decision,' 1992] repudiated the doctrine of terra nullius [that $18^{\text {th }}$ and $19^{\text {th }}$ century European settlement had been of unoccupied land], and acknowledged traditional and 'continuous' ownership of the land by Indigenous people. 
This was challenged vigorously by pastoralists and mining companies, and under a conservative Federal government, legislation was introduced which considerably limited the consequences of the High Court's decision. The requirement for 'continuous occupation' of the land was made more stringent (Wolfe 2000). ${ }^{2}$ There were debates over formal reconciliation between Indigenous and nonIndigenous Australians and about the need for white Australians to acknowledge and apologise for past wrongs and injustices. The Prime Minister, John Howard, refused to say 'sorry', to apologise for previous acts of State-supported racism and especially the 'Stolen Generations' [the forced removal by governments of Aboriginal children from their families]. And there were recurrent but especially intense debates about immigration and multiculturalism. The One Nation political party and its leader Pauline Hanson emerged in and helped shape this political climate.

Pauline Hanson and One Nation advocated a populist nationalism, promising to address the needs of the embattled ordinary, 'White Australian' and to put a stop to the egregious demands of the Aboriginal and multicultural 'industries'. Migration had to be dramatically reduced: there were too many 'Asians' preventing real Australians from getting jobs, and Aboriginal people received too many 'hand outs', another form of discrimination against real/ white/ordinary Australians. Ien Ang writes that under the leadership of Pauline Hanson, 'who drew her charisma from an aggressively lower-middle-class, anti-intellectual and anti-cosmopolitan populism, a vigorous grassroots political movement emerged of disenchanted, mostly white, rural and working-class people who revolted against what they saw as the disempowerment of their identities as "ordinary Australians"' (Ang 2000, p.5). At the time of the interviews we are discussing here (late 1997), One Nation had

\footnotetext{
${ }^{2}$ In the southeast of Australia, where our research was conducted, the early and comprehensive white settlement of the land meant that continuous occupation was almost impossible to establish - for example, the failure of the Yorta Yorta claim under the Native Title Act (Wolfe 2000).
} 
established a controversial presence in Australian politics. Its views had been widely publicised and were the subject of much media commentary and public discussion (Kingston 1999; Perera 1999). One Nation meetings had been held in many country towns, prompting fiery displays of support as well as opposition. Questions of race, nation and identity were at the heart of their politics: the interests of real Australians, whose needs had been neglected by successive Labor and conservative governments, were seen to be in conflict with those of migrants or Aboriginal people. In such a climate, what political attitudes were held by young people from rural and urban areas and with different ethnic and class identities; and how did they make sense of and locate themselves (and Others) within the overtly racialised political landscape of Australia?

\section{Identity, nationalism and whiteness}

Questions about nationalism, about what and who rightfully constitutes and belongs in the nation, are central to discussions about race and ethnicity in Australia. There is a heritage of belief that Australia is properly a white nation, and a history of associated practices, such as the White Australia policy ${ }^{3}$

\footnotetext{
3 'The Immigration Restriction Act was the key part of a package of legislation passed by the new Federal Parliament in 1901, aimed at excluding all non-European migrants. This package included the Pacific Islander Labourers Act and Section 15 of the 1901 Post and Telegraph Act, which provided that ships carrying Australian mails, and hence subsidised by the Commonwealth, should employ only white labour. Its sentiments were in line with Australian nationalism in the late 1880s and 1890s, and moves to restrict non-European immigration to most of the Australian colonies dating back to the 1850s. The mechanism restricting immigration could not be overtly based on race as this was opposed by Britain and frowned upon by Britain's ally, Japan. Instead, the basis was literacy, assessed by a Dictation Test. Similar Dictation Tests, based on legislation used in Natal in South Africa, had been introduced in Western Australia, New South Wales and Tasmania in the late 1890s. The Immigration Restriction Act enabled the government to exclude any person who "when asked to do so by an officer fails to write out at dictation and sign in the presence of the officer, a passage of 50 words in length in a European language directed by the officer". The Dictation Test could be administered to any immigrant during the first year of residence. It was initially proposed that the Test would be in English, but it was argued that this could discourage European migration and advantage Japanese people, and Americans of African descent. Instead, any 'European language' was specified. In 1905 this was changed to 'any prescribed language' to lessen offence to the Japanese. From 1932 the Test
} 
and government programs of assimilation. At the same time, being white is a kind of invisible, unmarked, yet normative identity. As the recent research on 'whiteness' has made clear, however, being white is an identity position whose history and effects require investigation. Whiteness, it is argued, has been made invisible in the process of exoticising the 'Other', documenting 'their' disadvantage, rather than examining white privilege (Fine et al 1997; Giroux 1997; Roman \& Eyre 1997). Underpinning such approaches is a view of 'race' as a construction, as not a fixed and selfevident category. Luke and Carrington (2000) argue that 'race' is a 'signifier of relational identity politics, a fundamental principle of social organisation and identity formation that moves people to act in certain ways' (2000, p.5). In this sense, '"Race" is both about "being" or claiming an identity (self-naming) and having a historically socially constructed identity (named as other by others)' (Luke \& Carrington 2000, p.6).

There has been growing interest in researching the construction of racial identities. But, as Anoop Nayak argues in the context of British race relations, much of this research has focussed on examining the racial and ethnic identities of minority groups, and consequently we know much less about the formation and experience of dominant white identities. We need now, he suggests, to interrogate dominant white ethnicities, to see how they are constituted and experienced. And writing from the US, Michelle Fine has argued that educational researchers need to examine 'the institutional processes by which "whiteness" is today produced as advantage through schools and the economy' (Fine 1997, p.58). In relation to contemporary Australia, Suvendrini Perera argues that 'rather being a selfevident or natural state, Whiteness is a historically produced category whose referents have been unstable and shifting throughout the story of Australian colonisation' (Perera 1999, p.185.). Although attention to whiteness risks re-centering the 'privileged' as again the fascinating object of study -as if

could be given during the first five years of residence, and any number of times. The Dictation Test was administered 805 times in 1902-03 with 46 people passing and 554 times in 1904-09 with only six people successful. After 1909 no person passed the Dictation Test and people who failed were refused entry or deported. The Act, frequently amended, remained in force until 1958'. Council for the Centenary of Federation (2000) Commonwealth of Australia http://www.foundingdocs.gov.au/text_only/places/cth/cth4ii.htm 
attention has shifted too much to the margins - it represents a significant shift in the way in which race and ethnic relations and politics are theorised (Giroux 1997; Apple 2000, pp.207-211). ${ }^{4}$

The debates about whiteness and the construction of race were on our minds as we listened to the students respond to our questions. We were attuned to how they did or did not position themselves and Others as white, as Australian or as outsiders, and how they negotiated the politics of racial and nationalist discourse. Reading these interviews against the debates in the current research literature, we develop two main lines of discussion here. The first is what the interviews suggest about the character of political debate and forms of reasoning about race and racism in Australia - what they tell us of the cultural logic of racism in one national setting. The second is the link between these views and processes of subjectivity, with how young people represent and construct themselves in relation to such discourses and the kind of identity and emotional investments they have in taking up particular 'political positions'.

\section{Judgements about racism and the reception of Pauline Hanson}

In interviews at all four schools, most of the students were quick to identify themselves as 'not racist', to separate themselves from the politics and opinions associated with Pauline Hanson. There was an implicit and shared sense that racism was unacceptable in polite or public conversation, and especially when being asked about these issues in an interview with white, professional women and in a school context. This was evident in both what they said and how they responded and engaged with us on the questions. There were nods and serious looks of recognition, assuming an air of gravity; an impression, on occasions, of them responding to 'current affairs' style questions, as if there had to be a 'right' answer. In most cases we were positioned and included in the 'we' who oppose

\footnotetext{
${ }^{4}$ For a discussion of 'whiteness and the conservative backlash' in the US see Giroux 1997. Giroux argues that 'In an era [1980s and 90s] of unprecedented unemployment, poverty, and diminishing opportunities for most Black Americans, right-wing Whites convinced themselves of their own loss of privilege. ...The progressive legacy of identity politics ... was either trivialized or dismissed as conservatives appropriated the politics of whiteness as a defining principle of Whiteness' p.286. However, in relation at least to Australia, the period to which Giroux is referring was also a time of actual unemployment, poverty and diminishing opportunities for poor white rural Australians; and the effects of these economic and social circumstances do need to be properly acknowledged when discussing the 'white backlash', see Ang 2000.
} 
racism: 'Well, like especially the rest of the population I don't agree with what she's [Pauline Hanson] saying, because I don't think money should be taken away [from Aboriginal services] or migration should be stopped' (Andrew). In such statements, students represented themselves as expert commentators upon, rather than as perpetrators of racism, and included us in this liberal gesture.

The 'second-guessing' of our views also occurred in another way, during an interview with an AngloAustralian country high school student who had attended a One Nation meeting with his family. Rodney smiles wryly when we mention Hanson's name, looking at us in a slightly bemused and awkward way, anticipating our views on the topic, and aligning us with urban political correctness.

It makes sense [what Hanson is saying]... even though it's not politically correct, it's all been blown out of proportion by the media [but] when you go there and listen to them ... you find that they've never been racist ... they've never said anything racist, they've just been misquoted (Rodney 97b).

Rodney held some of the most informed opinions of all the students on political matters, and knew in considerable detail about One Nation's policies; but he also suspects that we might disapprove and he recognises that his views will mark him out as different, as an outsider in his cohort. This is a subject position he is accustomed to occupying, due to his experience of being bullied and feeling the object of class envy (McLeod 2000). In this case, however, he seems to gain some pleasure from unsettling our views and in being able to articulate a counter view so forcefully.

Most of the students were familiar with a socially and politically acceptable or expected way to respond quickly to 'Hanson' -'she's racist'. But they were often less self-conscious and less familiar with such conventions when discussing the issue of racism at greater length. (A similar pattern was evident in discussions about sexism. There was often a quick and formal distancing of themselves from sexist views, but in discussion of issues, such as body image, they continued to express fairly conventional sexist views about girls and appearance without connecting the tension between the two stated positions. Formal knowledge of inappropriate politics - the right way to speak - is not necessarily evidence of a transformation in 'common-sense' and habitual political thinking and 
orientation (McLeod \& Yates 1997).) In the case of Andrew, quoted above, after declaring himself against racism, we asked his specific views on Hanson's attitudes to Aboriginal issues. He suggests that Hanson is a 'bit over the top because it's not everybody. It may be a small minority that she thinks about, she's talking about, but most of them are fine, yeah. Most of them are fine'. Andrew does not indicate if he has had direct or any contact at all with Aboriginal people. Nevertheless, he speaks authoritatively, apparently supporting them, but also constructing 'them' as a well-behaved group, a clearly defined 'them' to whom 'we' show fairness.

While Hanson was widely accused of being racist, she specifically denied that she was generic in her criticism of Aboriginal people, saying that her criticisms were about some who were lazy and/or who were getting special privileges. In many ways her stated position was a strong articulation of a liberal 'equal rights before the law' position. What is meant by being 'racist' is not necessarily clear or agreed upon, even though much discussion proceeds as if there were taken-for-granted criteria for determining racism. This was also the case in our interviews in that neither we nor the students really explained what we or they meant by the term 'racism'. On the one hand, a shared common-sense understanding was presumed, but on the other students were explicitly concerned with trying to work out the protocols and form of race discourses and when they were or were not being racist. These were ongoing tensions for us as well, in terms of how we formulated and posed questions about racism, analysed responses and wrote about young people's discourses of race and racism.

For many of the students, a central dilemma was how to respect the rights of the individual (in this case, Pauline Hanson and others who might wish to speak out) while not supporting racism. For students at the metropolitan schools in particular, responses to questions about Pauline Hanson were usually couched in terms of respecting 'freedom of speech', alongside a statement of personal disapproval. 'I strongly believe in freedom of speech ... But she's racist ... and I'm just totally shocked that so many people in Australia can back her ... and agree with what she has to say' (Marion 97b). Or, from Carole: 
She's horrible. Well that's my opinion anyway. She's racist. ... Like I believe in freedom of speech, but you've got a certain extent, like a certain fairness that you have to go to ... It's hard to explain. And so once you reach that line, it's pretty horrible if you go over it, because like there are a certain amount of things that you can say about certain races.

There was a pronounced concern with establishing and policing discursive and political protocols, and a self-consciousness and uncertainty about what was the correct way for them [the students] to speak about race and racism. Was it ever possible or appropriate to express racist views? Was there a 'proper' way to talk about 'race'?

For some students, particularly those at the country schools, Hanson was seen as 'going for it the wrong way' (Simon 97b;Andrew 97b) or as being a 'bit harsh' (Sue 97b; Emily 97b). These students admired Hanson's forthrightness and independence in speaking out-consistent with a tradition in Australia of admiring populist political mavericks. But there was concern that she could offend others and that her views would be misinterpreted. Hanson's right to speak openly in public was defended, but there was criticism of her for transgressing public space protocols ('going about it the wrong way') rather than her views being censored because they were 'racist' per se. Others expressed sympathy for her views, even as they noted that she was ' a bit rude'. These judgements of Pauline Hanson also need to be placed in the context of her reception as a political leader who did not fit the usual mould for politicians. She was a working-class woman, a single parent who owned a fish and chip shop, who spoke with a broad Australian accent, and was often criticised in the media for speaking too stridently and for acting inappropriately. In some respects, then, the students were picking up on what were dominant themes in public and media debates about Hanson, a debate that in its criticism of her for being racist, often denigrated her in fairly traditional sexist and classist ways (Kingston 1999).

[Pauline Hanson] has been a little bit harsh. I know what she's getting at because it's not, like I know, it's not our country exactly, we didn't pay for it, or anything, but I think they should, people should stay in their own country... maybe for holidays and stuff like that, but it may be racist, but it's just the way I think.

Yeah, she has a got a point, but she might, I think she's a bit rude just coming out and saying it like that

(Emily 1997b) 
While Emily maintains a clear view of national insiders and outsiders, she has a sense of the ambiguous claim 'we' have upon rightful ownership ('it's not exactly our country'). There is also a sharp degree of reflexivity in Emily's responses, a capacity to articulate her views, and then to acknowledge and reflect upon how such attitudes might be perceived by others and by us. This form of self-consciousness was evident in answers from several students, particularly those who were more ambivalent about Hansonism, and were struggling to work out their opinions in relation to a highlytuned sense of how their views could be received (see as well Rodney above). One student expressed sympathy for Hanson because she had been ridiculed by political cartoonists, and had been represented in sexist ways in media stories. Sue 's response emphasised the emotional and social context of opinions and reactions, acknowledging ambivalence in her own attitudes.

Sue: Oh Politics, um I don't know, I don't reckon it's actually fair what she says. I don't like her though. Everyone picks at her, they're always picking on her. When I saw one of those big posters with the big head and the little body.

$\mathrm{Q}$ : And other kids, what do you think the general feeling is among your friends? Sue: No one really likes her. They think she's a bit harsh.

In the interview, after declaring that she does not like Hanson, Sue looks directly at us, and pauses, trying to work out how she can, at the same time, convey her concern about how Hanson has been represented. (Significantly perhaps, Sue herself has been the subject of teasing at school, of kids making fun of her appearance, and as she gets older she becomes increasingly self-conscious about body size and physical appearance. During the course of our interviews she had become less comfortable in front of the video camera.)

For a few students, the political issue and debate about racism had very little impact at all. Three students needed to be told what it was about, two of those and two others conveyed that they were not interested at all in the topic, even though they had much to say about questions on other topics raised throughout the same interview. For other students it clearly sparked a strong and even intense response - from disapproval about how Hanson went about declaring her views, to condemnation of her values, through to criticism of her treatment by the media. There was, then, a range of emotional 
responses to Hanson and racism. Analyses of research interviews usually focus on the words from transcripts. But attention to emotional response and levels of affect-evident through tone of voice, animated or bored or indifferent looks and body language, willingness to say much; and grounded as well in knowledge of the biography of the interviewee over time ${ }^{5}$ - captures an important dimension of the subjective investment in national and racial discourses (see too Taylor et al 1996). And it offers insight into young people's orientation to political issues and ways of thinking more generally. In the case of Sue above, while acknowledging her disagreement with Hanson, she was also concerned with Hanson's feelings, with imagining what it would be like to be in her position and to be ridiculed. On the one hand, Sue's response displays a conventionally feminine gendered response-concern for and empathy with others, a concern in her case arising partly from her own experiences. On the other hand, it also suggests that responses to racism are non-unitary and multifaceted, that they are contextbound (the personality of Hanson, the sexism of the media), and that talking about racism involves and evokes more than a simple, rational 'for or against' answer.

\section{Us and them}

'Us and them' binaries framed students' understandings of racism and racial discourse, but they were shifting referents. Sometimes the 'Us' referred to those who opposed racism in contrast to 'Them', the racists: 'Even though we are multicultural and that, there are still a few racist people around.

Personally I don't agree with them' (Max 97b). We, the researchers, were usually and overtly included in the embrace of 'Us', or putting that another way, the students represented themselves to us as part of our 'we'. Even when students opposed racism, 'Australians' were positioned against 'Others', sometimes collapsing distinctions between Asians and Aboriginal people, grouping them together because of their contrast to ordinary, white Australians. However, for many students the 'us and them' binary mediated a different moral and political response to the relative status of Asians and Aboriginal people, whereby Asians were positioned as 'more Other'.

\footnotetext{
${ }^{5}$ The interviews were also video-taped and we were able to re-view the interview, to read the non-
} 
Kelly, a student at an elite metropolitan college, positioned Aboriginal people both as deserving of pity and as having a rightful claim upon Australia, and Asians as intruders.

I think that Aboriginals have just as much rights as we do, if not even more because they were here before we were. And I just think it's really sad what's happening with them and stuff.

I think Australia is becoming very um, populated with Asians. I think so, because they've got Japanese or Chinese writing under each street sign. In some place I went to they did and you know, it's a bit sad, but what can we really do to stop it now?

Q: Why do you find it sad?

Kelly: Um, I don't know actually. I was probably being racist. I don't know.

Her description of the influx of Asian migrants was prompted by a question from us asking if she had observed racism. Kelly said she had seen racism directed at 'Some Asians'. This leads to her view that 'Australia is becoming very populated with Asians'. A comment about racism against Asians displaces into fears of 'Asianisation'. (Asian migration to Australia is often represented as a new phenomenon, and Asians are frequently depicted as 'recent arrivals'. As Tsolidis (2001) argues, however, there was significant Chinese migration to Australia in the $19^{\text {th }}$ century, but they have not been treated as having such a long-standing history in the country.) The most disturbing aspect of migration for Kelly is that she has seen these 'street signs' in a 'normal town. It's not like Chinatown ... how they have cities and places in the city where that's fine ... But it's in like a normal full city area'. She concludes that: 'well, it's just that a lot of things are changing to suit them, do you know what I mean?' For Kelly, 'migrants' and especially Asians, are acceptable so long as they remain in the spaces (metaphoric and literal) designated for exotics, those groups of people who, in the right numbers, make our cities more interesting and appropriately culturally diverse. From Kelly's perspective, the us and them boundaries are threatening to dissolve.

Other students see Asians as threatening the livelihood of real Australians.

Well, they're [Aboriginal people] part of our country really because they were here first, and ... we're doing to the Aboriginals what Asians are doing to us.

Like taking on their jobs. (Emily 97b) Emily's distinctions place Asians as clear outsiders and Aboriginal people as having a morally superior claim to the nation. In a study of Australian children and popular racism, Fazal Rizvi (1993)

verbal responses, and to see the embodied emotional tenor and demeanour. 
argued that they drew upon a form of "'territorial belonging" (Walker 1988) to represent Asian immigrants as aliens and therefore deserving of a moral treatment very different from that applicable to Aborigines' (1993, p.133). In the examples from Emily and Kelly we can see that the dilemma of differential treatment is resolved through recourse to the justice of recognising prior national belonging to 'our' country. White Australians and Aboriginal Australians thus share common ground against 'Asians' ('them') and the threat of 'Asianisation'. Aboriginal people become highly differentiated from Asian Others, and, paradoxically, more aligned with, rather than opposed to, 'white Australians'.

Writing about national identity and multiculturalism in Australia, Ghassan Hage (1998) argues that 'Whiteness' is both an historically constructed category and a fantasy: a constellation of attributes and identifications that can be accumulated, in the Bourdieu-ian sense, whereby one might aspire to acquire certain prestigious forms of cultural capital. In this account, there are (up to a point) degrees of whiteness and degrees of otherness, and certain forms of conduct and ways of being can enhance or diminish one's capital and claim to whiteness (Hage 1998, p.20). Accumulating whiteness is linked to claiming a sense of national belonging, which in turn requires practices of exclusion and inclusion to sustain the distinctions between those who more properly belong and those who do not, those whose claims are less authentic and natural. For Hage, the 'spatiality' of these practices is crucial, and consequently he argues that strategies of exclusion and inclusion are better represented as nationalist rather than solely racist practices. Rather than having simply an either/or sense of national belonging, Hage proposes that 'people strive to accumulate nationality. They recognise themselves as more national than some people and less national than others' (p.52). Certain physical attributes fairness - or language competence - knowledge of English - can be converted into 'a form of national "cultural capital"' (p.53). Whiteness is not simply skin colour, though clearly colour is an important 'capital', but there are no clear-cut, stable distinctions between 'Black and White'.

"Whiteness" is an everchanging, composite, cultural historical construct. ... [But] White has become the ideal of being the bearer of 'Western' civilisation. As such, no one can be fully White, but people yearn to be so. It is in this sense that Whiteness is itself a 
fantasy position and a field of accumulating Whiteness. It is by feeling qualified to yearn for such a position that people can become identified as White. Hage,1998 p.58.

In Emily's and Kelly's responses (above) we can see some of the ways in which they situate themselves as 'spatial managers' of the Australian nation ('people should stay in their own country'), alongside, as we have suggested, a certain ambivalence about 'our' national belonging. Emily lived in a small country town and attended a school in a working-class area of a nearby larger provincial city. While the fear she expresses of Asians taking jobs was not an uncommon response, Emily lived in a region that had suffered from the effects of economic restructuring, and she could observe unemployment and its consequences in her immediate environment. Such concerns, as many commentators have noted (Perera 1999), have fuelled the popularity of One Nation in rural areas. But Emily also struggles to reconcile a concern about jobs with an awareness of different degrees of and claims for exclusion and inclusion. On the one hand, then, Emily's views represent a version of Hage's spatial manager of the white nation. On the other hand, that assessment does not fully capture a sense of her trying to work out a complex political issue nor her reflexivity about either the ambiguous status of white Australians - as dispossessors, and as owners of the nation - or of her own political views and emotional responses.

We found listening to and watching the embodied responses of students offered a vivid sense of the significance of the issue for them, compared to acknowledging only the 'content' of what they said. Throughout this interview, Emily speaks confidently to us about the topic, displaying more engagement and interest in our questions than she usually has in the preceding four years. When Kelly talks to us about Asians taking over normal towns she becomes particularly animated and talkative, engaging us directly. When we first raised the topic of Pauline Hanson, she is uncertain about whom we are speaking, and we have to explain the debate. She does not seem interested in this topic at all or in most of the other political questions we ask. Kelly tries to give us answers and obviously has some opinions, but she also appears uncertain, says she does not think about these things much. 'I don't know what I was going to say'; 'I don't really think about it'. She answers in a desultory fashion, but in a way also attuned to what she anticipates we expect to hear: 'I was probably 
being racist', self-consciously censoring herself in front of us. The topic of Asians 'taking over' enlivened her responses. In these two examples, the different registers of response point to the shifting emotional significance that political topics have, offering insight into attitudes to race and racism and to identity formation. It is this latter aspect of political reasoning that needs to be properly acknowledged in analyses of whiteness, whether understood as 'fantasy' or as a 'real' identity.

Like Hage, the cultural studies critic Ien Ang discusses the reception of Pauline Hanson in Australia in terms of national identity. But she casts it differently, looking from another angle at the relation between 'identity' and 'nation'. Whereas Hage's focus is on whiteness as an identity comprising 'capitals' that can be accumulated, Ang attends to the emotional attachments to political positioning, and the resonance of macro national changes with subjective desires. Reflecting on the political and emotional climate in Australia preceding the rise of One Nation, Ang describes rhetorical moves to redefine Australian identity as a 'transnation', and the emergence of a discourse declaring a new sense of its place in the world, especially in relation to Asia.

Indeed as a migrant who was eager to find my place in this society I was excited to notice, in the early 1990s, that a new Australian nationalism could so elegantly, and with such apparent ease, shift its identificatory allegiance from being a racially and culturally exclusionary 'White Australia' to an inclusive and cosmopolitan 'multicultural Australia in Asia' .... Indeed, what seemed at stake in the new Australian nationalism was identity construction rather than identity expression, the sense that 'what we might become' is more important than 'who we are'. (Ang 2000, p.7)

For some Australians, particularly those who were not members of the cosmopolitan elite, where Ang critically locates herself, the 'new Australian nationalism' did not represent a moment of hope, the possibility of 'becoming' something new and exciting. Rather the key tropes for identity were loss and longing for the past, and a panic about 'who we were', and these issues, Ang argues, were largely ignored in the 'moral(istic) critiques of racism' (Ang 2000, p.5).

What we found helpful in Ang's discussion of Hansonism was her attention to the subjective investments and histories that inform political and the 'rhetorics of racism'. This adds an important element to analyses of racism and whiteness. It helps us see the interaction of complex emotional, 
psychological and material factors in the shaping of 'white identities', a process that is not easily captured by Hage's metaphor of identity as 'capital accumulation'. In the following section, we consider some of these issues in discussing how two students positioned themselves in relation to racism, to being 'Australian', and to 'us and them' identity positions.

\section{Researching racism and constructing the Other}

The majority of the students we interviewed were white Anglo-European, although such identity categorisations are not straightforward. Several students had one or both parents born outside of Australia, including in Europe, the Middle East, North America, South and South East Asia. But here the politics of appearance and Whiteness as 'capital' becomes important. Some students were less noticeably 'ethnic' (a common-place designation of ethnic-minority compared to ethnic-majority groups in Australia) than others, and students in the group identified and represented themselves to varying degrees as white or Australian or Other. Such identification on the continuum of 'white/Other' also appeared to have an effect on how students spoke about racism. For example, one Australian-born girl, Bree, with an Arabic mother and a European father, was fair and had an 'unmarked' Australian accent and consequently, in Hage's terms had considerable capital for passing, looking and sounding 'white Australian'. She articulated, over the period of our interviews, an increasing sense of herself as a 'multi-cultural person', one who strongly disliked racists, and who knew lots of people from many different cultures. 'My boyfriend is actually Black [Maori] and he, he's alright actually'. Throughout the interview she is animated and engaged, and the questions and topic have visibly 'struck a chord' with her. She is smiley rather than indignant, and represents her ethnic difference and friendship with 'different nationalities' as interesting cosmopolitanism.

I really dislike Pauline Hanson. I am half and half [...] so I'm not of Australian culture, background or whatever. Um, I'm a [...] citizen as well as an Australian citizen, so I've dual citizenship. I just don't like her views, I am totally against racist people. I don't want anything to do with them. I don't know, I just don't like the way she is and she really upsets my mum when she comes on TV too. I think she has upset a lot of people politically and she hasn't needed to do that. 
She thought that there was not much racism in Australia, but that 'There still is racist people and those I just don't want anything to do with, because I despise them'. Because of her capacity to pass, in Hage's sense, as 'white', Bree could comment on racism as someone who was both relatively secure in the national belonging, and who could speak candidly on racists in Australia because of her identity, her parents' experiences and her mixing with kids from 'different nationalities'. She was able to move between both subject positions; to claim Otherness, and to claim a strong degree (she can 'pass') of national belonging. Speaking of racism from experience did not indelibly or negatively mark her as an Other.

Yet, although she had a strong investment in her identity as 'against racists' she expressed attitudes to Aboriginal people that were similar to those adopted by Hanson and One Nation. She thought 'They' were getting 'too many rights', even though 'I've got nothing against Aboriginal people'. Bree's critique of racism is most finely tuned when it affects her life experience directly. In her reasoning Aboriginal people, not migrants, are the true 'Other'. She re-positions herself here as an authentic Australian with a history of belonging to the nation, compared to her earlier self-description as 'not of Australian culture, background'. Note the repetition of 'our ancestors', the expansiveness and authority of the 'we' and 'us', encompassing us as the researchers and as presumed managers, like herself, of the white Australian nation.

I think they get too many rights over us and it's always we have to apologise for what our ancestors did to their ancestors. I think it's a totally different generation now, and we're totally different people and we can't keep apologising for what our ancestors did to their ancestors. I think they get way too many rights over us now and they're talking about equal rights, well it's not equal.

Bree identifies as a non-Australian who is 'at home' and naturally belongs in Australia. Her casting of Aboriginal people as more properly Other secures her position in the white Australian landscapeIndigenous Australians are less 'white' than migrants. Compare this to the views expressed by Emily and Kelly, both Anglo-Australian girls, who position migrants as more Other, 'less white,' than Aboriginal Australians. The designation of 'them' is explicitly linked to self and national identity - all Australians (black and white) compared to migrants/outsiders, and all whites compared to 
Indigenous Australians. Bree's reasoning indicates that responses to racism are not unitary, and that apparently divergent views of the nation and of (shifting) Others can be held simultaneously.

Bree's reference to 'our ancestors' constructs an historical affiliation to Australia, giving her an (imaginary) past Australian identity. The past is invoked not to vindicate the legitimacy of white authority, but rather to signal the possibility of a different kind of nation, a new generation -'we're totally different people' - and a positive future for herself as someone 'not of Australian background'. She positions and understands herself as a cosmopolitan subject who experiences cultural and ethnic difference not as negative Otherness (as has been the experience of her mother) but as a positive and interesting attribute of identity. In the provincial, predominantly Anglo-Australian town where she grew up, Bree can lay claim to a certain exotic, but not threateningly different, status. Attitudes to race and Other do not always fall into a neat binary logic. Here they are also intertwined with Bree's forging of her identity, of becoming both Australian and not Australian, and a future-oriented, 'multicultural' person impatient with Aboriginal claims of 'prior' racism.

The notion of identity as a process of becoming features in much contemporary cultural studies, in part due, as Ang argues, to the influence of Stuart Hall's work. She suggests that:

Hall rescues the possibility for "identity" - that is, the way we represent and narrativize ourselves to ourselves and to others - to be a resource of hope, to be the site of agency and attachment that energize us to participate in the making of our own ongoing histories, the construction of our continuously unfolding worlds, now and in the future' (Ang 2000, p.1).

Our reading of Bree's representation of herself echoes with such accounts of identity. Her identity as a 'multicultural' person is discursively linked to a sense of herself as 'becoming', and as having an optimistic sense of future possibilities defined against a backward-looking race politics. But as Ang argues, the emphasis on 'becoming' in cultural studies is also fundamentally utopian, and tends to neglect that identity processes can also be shaped by fear of the future and a reluctance to embrace change because of its perceived negative effects. The politics of race and the discourses of multiculturalism and cosmopolitanism are obviously intertwined with identity politics, but they are 
also affiliated with the different positionings people take up in relation to their sense of the future and the past. This can produce a buoyant sense of 'becoming', implicit in the new cosmopolitanism, and in the multicultural identity and future imagined by Bree. It can, however, also generate fear of the future and longing for the past, emotional responses which Ang sees in the supporters of Hansonism, and her analysis of this provides an important counterpoint to idealistic conceptions of identity formation as simply a process of 'becoming'.

A different kind of response to race discourses in Australia was offered by Nuri, who was also born in Australia, has Arabic parents and is more obviously identified as 'ethnic' by physical appearance and accent. He attends weekend school to study his family culture and language, he mixes socially and at school with kids from the same background. In interviews, he is often reticent, and sometimes awkward with our style of questioning, but he keeps coming voluntarily to all the interviews, even those conducted after he finishes school. Throughout the interview he positions himself as someone who comments on racism, rather than someone who has experienced racism

Q; What are your views about her [Pauline Hanson] and the debate that she's generating? $\mathrm{N}$ : I don't like it

Q: Have you talked about it much with your friends? Does it come up at home and do you talk about it at home?

$\mathrm{N}$ : At home? It has come up a couple of times at home. Um, not with friends.

Q: Do you think there is much racism in Australia?

N: Um, besides Pauline Hanson, no.

Q: You think not?

N: No.

One possible explanation for Nuri's reluctance to say more and his description of there not being much racism in Australia is that it locates him less as an outsider. Unlike Bree, he does not have sufficient white capital to jeopardise his national belonging by identifying himself as an Other who has experienced racism. Positioning himself as an observer of racism joins him with an 'Us' who oppose racism and discrimination against 'Them', and attests to his successful 'fitting in' - at school and in the culture generally

But Nuri's responses also raise methodological issues about the effect of asking questions in particular ways, and of (unintentionally) inciting and producing certain responses. In retrospect, and in listening 
to and reading the interview transcripts, it was clear that our mode of questioning made it difficult for Nuri to respond in other ways. (Here too we need to acknowledge the accumulated history and effects of our interviews over the preceding four years, where two white women came twice a year to conduct social science research interviews with him at school. In these interviews Nuri is polite and co-operative but also a little uncertain as to what we actually want and what kind of responses he should be giving). His responses to our questions in this interview are noticeable briefer than usual, often a couple of words, and he appears uncomfortable, pausing in responses, laughing nervously, looking away from us, and is obviously relieved when the questioning stops. During the interview we too felt awkward, and unsure of how to manage the silences and uneasiness. We could see that he was uncomfortable but ending the interview early did not seem the right thing to do either, as that too could be another form of silencing.

We asked questions about Pauline Hanson and migration as if he were an expert on the experience of racism (an Other) and he responded in a way that showed his mastery of polite and proper discourse about racism when speaking with white women in a relatively formal setting. It is possible as well that his responses reflected a sense of (or desire for) national belonging as an Australian. He does not take up the position of 'discriminated against Other' who might tell us as researchers some truth about racism. This was the position our line of questioning, unconsciously perhaps, wanted him to speak from. We did not regularly ask other students if they spoke about Hansonism at home, but by posing this question to Nuri ('the ethnic family must have encountered racism, tell us all about it') we betrayed our own desire for him to speak as, and be positioned as, the Other. In his answers too there was another kind of second-guessing of our desire to hear certain answers (that multiculturalism works? that Australia is a tolerant society?) and to not offend us as white Australians, to not be rude to members of the host country. So the dynamics of the research interview simultaneously produced a form of official multicultural discourse and an Othering of the research participant ; and revealed some of Nuri's reasoning about the context-specific and appropriate way to respond questions to racism. 
In reflecting on their experiences of interviewing black adolescent girls as part of a study of girls 'at risk', Jill Taylor, Carol Gilligan and Amy Sullivan write of the silences, of what is seen and what is not noticed when white researchers interview black participants. In one telling example, they describe the failure of a white researcher not to notice or to follow up when a young black woman introduced a 'race' topic into an interview. The young woman refers three times to 'a racial comment' when describing an exchange between herself and a teacher, but the researcher does not return to this in any of her follow-up questions (Taylor et al 1996, pp.233-35). This occurred in a study explicitly and selfconsciously concerned with relationships, and with developing a 'relational method of enquiry'. It was a study attuned to the effects of the researcher, to the dynamics of the relationship between researcher and researched and to the significant methodological effects of social and power differences in that relationship. Yet, it was only when they were on a research retreat to discuss the transcripts with an invited group of black and white scholars not directly involved in the interviewing, that the silencing of the 'racial comment' was noticed by one of the black women.

In the example from our interviews quoted above, the methodological and political effect was not so much one of 'not noticing' but of wanting to hear, to incite a particular response that would satisfy our curiosity about the experience of racism. In both examples, however, the question is raised of how racist and Othering practices enter the research scenario even when there is a heightened sense of researcher reflexivity; and even when questions about race are raised directly. In our case, posing questions about race and racism to young people who are likely to be routinely constituted as 'Other', did not at all remove the risk of Othering. In wanting to hear the voice of the Other, the interview worked paradoxically to produce what Nuri judged we wanted to hear and what he thought was the right thing to say. 


\section{Concluding comments}

We have looked at how young people negotiate racial discourses and political reasoning in the context of intensified public political debates about race, ethnicity and nation in Australia, and a heightened attention to whiteness in that politics and in the research literature. In exploring some of the relations between political discourses and self-positioning, we have pointed to the significance of desires and aspirations as well as fears in these forms of political and self-identification. One of our concerns was to understand something of the national cultural logic of racism. We have argued that although 'us and them 'binaries are shifting and unstable, focussing on their deployment within young people's discourses helps us to see the identifications and contrasts with which they are working.

In her comparative study of the rhetoric of racism and anti-racism in the US and France, Lamont interviewed white and minority (African American and North African respectively) working-class men in both countries, and found that both white majority groups expressed racism 'largely though a moral critique of the values of racial minorities, particularly concerning self-reliance, individualism, and family values' (p.44). Deploying similar universalistic and moral arguments, both AfricanAmericans and North Africans described their 'own culture as morally superior to that of majority groups'. There were, however, significant national differences in 'the cultural tools' available for rebutting and demonstrating racism and racial inequality. In the United States, 'interviewees more often explain racial differences with reference to biology, history, and psychology, and use marketrelated arguments' [in the sense that performance at work and in the labour market is seen as an equaliser of racial difference] (p.45). In contrast, French workers 'exclusively refer to specifically cultural and religious explanations in accounting for racial inequality' (p.45). In our discussion of young people's negotiation of racial discourses, what larger themes and tropes, what cultural logic frames their reasoning, and their constructions of difference? 
The deployment of 'us and them' binaries is marked by hierarchies of Otherness, of distinctions between who is more or less 'us' than Others, and on the comparative moral and political claims of 'white' Australians, migrants and Aboriginal people: the interplay of the three groups is crucial. One of the features and contexts of the 'logic of racism' in Australia is a strong historical debate about and a contemporary concern with the morality of territorial claiming. And, as Hage (1998) has argued, this continuum is based upon 'spatialised' strategies of inclusion and exclusion. We have shown, for example, how explanations of who is more properly Australian than Others frequently draw upon a historical sense of 'arrival' or of 'already being here', and an associated morality of what then constitutes rightful claims upon the country. Such rightful claims on the national space can, the rhetoric suggests, either exempt one from or explain or justify racism, and we have shown students trying to work out the different moral and political claims to belonging. The Australian nation here is not understood solely as an imaginary: it is represented strongly in physical and geo-spatial terms. From the perspective of Anglo-Australian students, Aboriginal people are less ‘Other' than migrants (and especially the newly arrived Asians), while for someone such as Bree, whose parents are relatively recent migrants, Aboriginal people are clearly marked as the most Other. Their political claims constitute a backward-looking politics, a fixation on the past, whereas she is oriented to the possibilities of the future and a new cosmopolitanism that is distinguished from previous generations.

When we first decided to ask young people about race and racism, it was in the context of devising some questions about political issues for one interview in a longitudinal study of secondary school students' attitudes and developing subjectivities. Our interest was both in forms of political reasoning and in what that suggested about developing biographies. We have tried to draw out some of the ways in which young people position themselves in relation to discourses about race and the Other, and have offered some examples of how this connects to processes of identity formation, and to the kind of person they imagine themselves to be. We have also emphasised the emotional dimension, the levels of affect, of political discourses and the subjective histories and desires people bring to their engagement with the politics of race and nation. Finally, we have presented some reflections on our 
experience of trying to research racism, in terms of the methodological dilemmas of the embodied researcher, and of researching and constructing the Other. As white middle-class women, our presence provoked certain kinds of responses and reflexivity from the participants. For some, there was a finely-tuned sense of answering in the right way, of anticipating our views, and tailoring answers to satisfy, please or shock us, or of reflexively censoring or commenting on their views. But our presence and mode of questioning also silenced or made it difficult for Others to speak. In the example of Nuri, the dynamic of the interview worked to produce him as an Other even as we sought to speak directly and openly about racism, to give 'voice' to what we imagined was his identity and experiences. Research interviews can construct what they set out to investigate, and researching racism requires us to be attentive to the identity positioning and investments of both the interviewees and the interviewers.

\section{Reference List}

APPLE, M. (2000) Educating the 'Right' Way: markets, standards, god and inequality, (New York, Routledge).

ANG, I. (2000) Identity Blues, in: P. GILROY, L. GROSSBERG \& A. McROBBIE (Eds) Without Guarantees: in honour of Stuart Hall, pp.1-13, (London, Verso).

DOLBY, N. (2000) The shifting ground of race: the role of taste in youth's production of identities, Race Ethnicity and Education, vol. 3:1, pp.7-23.

FINE, M. (1997) Witnessing whiteness in: M. FINE, L. WEIS, L. POWELL ,L.M. \& WONG, L. (Eds) Off White: Readings on Race, Power and Society (New York, Routledge).

FINE, M. WEIS, L. POWELL , L.\& WONG, L. M Eds (1997) Off White: Readings on Race, Power and Society (New York, Routledge).

GIROUX H. (1997) 'Rewriting the discourse of racial identity: Towards a pedagogy and politics of whiteness', Harvard Educational Review, vol.67:2, Summer, pp.285-320.

HAGE, G. (1998) White Nation: Fantasies of White Supremacy in a Multicultural Society (Sydney Pluto Press).

KINGSTON, M. (1999) Off the Rails: The Pauline Hanson Trip (Sydney, Allen \& Unwin).

LAMONT, M, (2000) The rhetorics of racism and anti-racism in France and the United States', in M. LAMONT \& L. THEVENOT (Eds) Rethinking Comparative Cultural Sociology: repertoires of evaluation in France and the United States, pp.25-55 (New York, Cambridge University Press). 
LUKE, C. \& CARRINGTON V. (2000) Race matters, Journal of Intercultural Studies, vol. 21:I April, pp.5-24

McLEOD, J. (2000) Subjectivity and schooling in a longitudinal study of secondary students', British Journal of Sociology of Education, vol. 21: 4 Dec, pp.502-521.

McLEOD, J. \& YATES, L. (1997) Can we find out about girls and boys today or must we just settle for talking about ourselves? dilemmas of a feminist, qualitative, longitudinal project', Australian Educational Researcher, vol.24: 3, pp.21-42.

NATIONAL COUNCIL FOR THE CENTENARY OF FEDERATION (2000) Immigration Restriction Act [White Australia Policy] (1901) Commonwealth of Australia, http://www.foundingdocs.gov.au/text_only/places/cth/cth4ii.htm

NAYAK, A. (1999) 'White English Ethnicities': racism, anti-racism and student perspectives, Race Ethnicity and Education, vol 2:1, pp.177-202

PERERA, S. (1999) Whiteness and its Discontents: notes on politics, gender, sex and food in the year of Hanson, Journal of Intercultural Studies, vol. 20:2,p.183-198

RIZVI, F. (1993) Children and the grammar of popular racism in: C. McCARTHY \& W. CRICHLOW (Eds) Race, Identity and Representation in Education, pp.126-139 (NewYork, Routledge).

ROMAN, L.G. \& EYRE, L. (Eds) (1997) Dangerous Territories: struggles for difference and equality in education (New York, Routledge).

ROMAN, L.G. \&S TANLEY T. (1997) Empire, emigres and aliens: Young people's negotiation of official and popular racism in Canada, in: L. G. ROMAN \& L. EYRE (Eds) Dangerous Territories: struggles for difference and equality in education (New York, Routledge).

TAYLOR J.M., GILLIGAN, C. \& SULLIVAN, A.M. (1996) Missing voices, changing meanings: developing a voice-centred, relational method and creating an interpretive community' in: S. WILKINSON (Ed) Feminist Social Psychologies: International Perspectives, pp.233-257 (Buckingham UK, Open University Press).

TSOLIDIS, G. (2001) Schooling, Diaspora and Gender: Being Feminist and Being Different (Buckingham UK, Open University Press).

WALKER, J. (1998) Louts and Legends: Male Youth Culture in an Inner-City School (Sydney, Allen \& Unwin).

WOLFE, P. (2000) The limits of Native Title, Meanjin, vol.59:.3, pp.129-144.

YATES, L. (2000) Representing 'class' in qualitative research' in: J.McLEOD and K. MALONE (Eds.) Researching Youth, pp.149-162 (Hobart Aust., Australian Clearinghouse for Youth Studies).

YATES, L. \& McLEOD, J. (1996) "And how would you describe yourself?" Researchers and researched in the first stages of a longitudinal research project', Australian Journal of Education, vol 40: 1, pp.88-103. 


\section{University Library}

\section{- M M I N E R VA A gateway to Melbourne's research publications}

Minerva Access is the Institutional Repository of The University of Melbourne

Author/s:

MCLEOD, JULIE;Yates, Lyn

Title:

Who is "us"? students negotiating discourses of racism and national identification in Australia

Date:

2003

Citation:

McLeod, J., \& Yates, L. (2003). Who is "us"? students negotiating discourses of racism and national identification in Australia. Race, Ethnicity and Education, 6(1), 29-49.

Publication Status:

Published

Persistent Link:

http://hdl.handle.net/11343/34736 